V. - Genetic improvement

\title{
Establishment of correction factors of litter size for age of dam at farrowing in french pig breeds
}

\author{
C. LEGAULT, J. OWEN \\ Station de Génétique quantitative et appliquée, I.N.R.A., C.N.R.Z., \\ 78350 Jouy en Josas \\ U. P. R. A. Porcine, \\ 6, rue Ampère. \\ 75017 Paris
}

The average numbers of piglets born, born alive and weaned in $35 \mathrm{ft}$ Large White litters, 729 Blanc de l'Ouest litters, 9222 French Landrace litters, 1795 Pietrain litters and 4 I 29 Relgian Landrace litters were used to establish the equations representing the cvolution of prolificacy ( $\mathrm{Y}$ ) in terms of age of dam at farrowing $(x)$ expressed in clays: these equations can be formulated as a $4^{\text {th }}$ clegree polynomial :

$$
\mathrm{Y}=\mathrm{A}+\mathrm{B} x+\mathrm{C} \mathrm{x}^{2}+\mathrm{D} \mathrm{x}^{3}+\mathrm{E} x^{4}
$$

The five breeds studied can be divided into three distinct groups by decreasing order of prolificacy. The first group includes the two breeds of the "clual purpose "type (Large white and French Landrace). These two breeds are very close to cach others at weaning in spite of a slight superiority of the former at birth. The second group contains the two breeds of the "cloublemuscle " type (Pietrain and Belgian Landrace) exhibiting about I piglet less per litter at farrowing and weaning than the two previous breeds. In the last group we fincl the "Blane de l'ouest " pig of very low prolificacy, one of the main causes of its recent disappearance.

Examination of the representative curves confirms the already well established results: litter size at birth increases progressively towards a maximum reached between the age of 1 ooo and 1200 days according to breeds. The maximum number of piglets weaned per litter is reached carlier: between 700 and I ooo days according to breeds.

On the basis of these results, a method of correction of litter size for the effect of age of dam can be suggested, method which is more precise than that based on the effect of litter order. This correction is adapted to each bred and its application is all the more justified as the utilization of the sows for reproduction occurs carlier and as the prolificacy level of the breed is higher. 